\title{
Relationship between depression and severity of COPD among Egyptian elderly patients
}

\author{
Ahmed A. Abdelgaleel ${ }^{1}$, Sara A. Hamza', Mohamed S. khater ${ }^{1}$, Nehad M. Osman ${ }^{2}$, Mohamed \\ Mortada ${ }^{1}$ \\ 1Department of Geriatric Medicine, Faculty of Medicine, Ain Shams University. \\ 2Department of chest medicine, Faculty of Medicine, Ain Shams University, Cairo, Egypt
}

\begin{abstract}
Background: It is well known nowadays that systemic inflammation plays a major role in the psychopathology of developing depression, and it is also well known that systemic inflammation is the core of chronic obstructive pulmonary disease (COPD) pathophysiology. So, many COPD patients are suffering also from depression.
\end{abstract}

Aim: to clarify the relationship between depression and severity of COPD stage among Egyptian elderly COPD patients

Methods: Forty eight elderly stable COPD patients aged 60 years or more were enrolled in this study. Severity of pulmonary obstruction was determined based on Global Initiative for Chronic Obstructive Lung Disease (GOLD) guideline; 2017 using spirometric measurements. Arabic version of Geriatric Depression Scale (GDS) was used to determine the psychological status of each participant.

Results: The mean age of COPD patients was $64.38 \pm 3.52$ years, and disease duration was $18.60 \pm 11.31$ years. Depression was found among $62.5 \%$ of the study participants.

Conclusions: Depression was found to have no statistically significant relationship with the severity of pulmonary obstruction in COPD $(p=0.123)$.

Keywords: Chronic obstructive pulmonary disease, depression, pulmonary rehabilitation.

\section{Background}

COPD is a multicomponent disease, and patients may have a very wide range of comorbid conditions that can affect prognosis and make a negative impact on morbidity and mortality [1]. Patients with COPD usually suffer from progressive reduction of lung function, decreased exercise capacity, frequent disease exacerbations, and development of extra-pulmonary comorbidities such as osteoporosis, cardiovascular diseases, and infections [2] with development of many other psychological troubles most commonly depression and anxiety [3] [4]. The prevalence of COPD in the elderly markedly increases with age and could reach up to $15 \%$ in those over 65 years [5].

Depression is one of the most important and most common comorbidities that may complicate COPD patients [6] with a reported prevalence of depression in patients with COPD ranges from $10-42 \%$, which is much higher than in general population [7] [8], but it is often undiagnosed and undertreated [9]. The key pathophysiological mechanisms underlying the relationship between COPD and depression are not fully understood [10], but it occurs most probably due to systemic inflammation, perhaps via TNF- $\alpha$, and oxidative stress [11], with many factors that contribute to depression in COPD such as socioeconomic status, female sex, and living alone [10].

Depressive disorders in COPD often present with moderate to severe symptoms leading to a decreased functional capacity [9] [12], marked poor health outcomes, lowered quality of life, significantly increased healthcare costs and increased mortality [6] [10]. 
Many studies suggest that the presence of depression in patients with COPD is correlated with an increased incidence of COPD exacerbations and even increased mortality [11] [13]. Pulmonary rehabilitation with or without psychological rehabilitation can help improving depressive symptoms in COPD. Cognitive behavioral therapy (CBT) is considered an effective therapeutic intervention for management of depression in COPD. Beyond pulmonary rehabilitation, the optimal approaches for management of depression in COPD is yet unclear.

The effect of COPD severity on the result of the Patient Health Questionnaire Depression Scale 9 (PHQ-9) tool for the diagnosis of depression was recently investigated in a study carried out in Germany in 2019 [14]. In this study we aimed to address the relationship between presence of deprssion in COPD patients as a comorbidity and the severity of COPD stage.

\section{Methods}

An observational study was conducted among 48 elderly patients diagnosed with COPD. The study was approved by the local ethics and management boards, based on informed consents and permissions of participants and in respect to legislation for confidentiality of patient's data use and publishing.

All subject were 60 years or more, and diagnosed to have COPD. Diagnosis of COPD was done according to Global Initiative for Chronic Obstructive Lung Disease guideline; 2017 [15]. While, those who had acute exacerbation of COPD (AECOPD) in the last month and those who had any previous psychological diseases were excluded.

\section{Tools and Measures:}

The subjects were assessed for their demographic data, medical history, smoking status, COPD staging using GOLD classification after performing a spirometry. Then all subjects were also screened for depression using Arabic version of Geriatric Depression Scale (GDS).

\section{Statistical Methods}

Data were fed to the computer and analyzed using IBM SPSS software package version 20.0. (Armonk, NY: IBM Corp) Qualitative data were described using number and percent. The Kolmogorov-Smirnov test was used to verify the normality of distribution Quantitative data were described using range (minimum and maximum), mean, standard deviation and median. Significance of the obtained results was judged at the $5 \%$ level.

\section{Results}

A total of 48 COPD elderly patients aged 60 years or more were enrolled in the study.

The demographic data of the study population showed that all participants were between 60 and 75 years old with mean age was $64.38 \pm 3.52$ years. Among all participants, only $2(4.2 \%)$ participants were females with the remaining $46(95.8 \%)$ participants were males and $39(81.3 \%)$ participants were retired. Education levels differed significantly between participants as 22 $(45.8 \%)$ of them were illiterate and $12(25.0 \%)$ were highly educated.

Table 1: smoking status of the studied participants Total 48

\begin{tabular}{|c|c|c|}
\hline \multirow[b]{2}{*}{ Smoking } & No. & $\%$ \\
\hline & & \\
\hline Cigarette smoker & 26 & 54.2 \\
\hline Non smoker & 12 & 25.0 \\
\hline Ex cigarette smoker & 4 & 8.3 \\
\hline Cigarette + Shisha smoker & 6 & 12.5 \\
\hline Smoking index & \multicolumn{2}{|c|}{$(n=36)$} \\
\hline Min. - Max. & \multicolumn{2}{|c|}{$20.0-150.0$} \\
\hline Mean \pm SD. & \multicolumn{2}{|c|}{$55.24 \pm 33.48$} \\
\hline Median & \multicolumn{2}{|c|}{42.50} \\
\hline
\end{tabular}

A percentage of $25 \%$ (only 12 of participants) were non-smokers, while 26 participants $(54.2 \%)$ were current cigarette smokers, 6 participants $(12.5 \%)$ were current cigarette and shisha smokers, and only 4 participants $(8.3 \%)$ were ex-cigarette smokers. Smoking index for participants who used to smoke was $20-150$.

Table 2: Spirometric classification of the studied participants

\begin{tabular}{lll}
\hline Spirometric classification & $\begin{array}{l}\text { Total } \\
(\mathbf{n = 4 8})\end{array}$ \\
& No. & \% \\
& 2 & 4.2 \\
Gold $\mathbf{1}$ & 9 & 18.8 \\
Gold 2 & 9 & 18.8 \\
Gold 3 & 28 & 58.3 \\
\hline Gold 4 & & \\
\hline
\end{tabular}

A percentage of $25 \%$ (only 12 participants) were nonsmokers, while 26 participants $(54.2 \%)$ were current cigarette smokers, 6 participants $(12.5 \%)$ were current cigarette and shisha smokers, and only 4 participants $(8.3 \%)$ were ex-cigarette smokers. Smoking index for participants who used to smoke was $20-150$.

As regard COPD duration, participants were found to have COPD for at least 3 years and maximum for 45 years with the median number of years of having COPD was found to be 20 years.

GOLD classification was carried out by spirometric measurements to categorize participants as regard severity of COPD, and it was found that most of patients $(28$ participants $=58.3 \%)$ were GOLD 4 (most severe COPD stage). 
Abdelgaleel AA et al., EJGG.2019; 6(2):26-29

Table 3: Relation between Spirometric classification and GDS

\begin{tabular}{|c|c|c|c|c|c|c|c|c|c|c|}
\hline \multirow[t]{4}{*}{ GDS } & \multicolumn{8}{|c|}{ Spirometric classification } & \multirow[t]{4}{*}{$\mathbf{X} 2$} & \multirow[t]{4}{*}{${ }^{\mathrm{MC}} \mathbf{p}$} \\
\hline & \multicolumn{2}{|c|}{ Gold 1} & \multicolumn{2}{|c|}{ Gold 2} & \multicolumn{2}{|c|}{ Gold 3} & \multicolumn{2}{|c|}{ Gold 4} & & \\
\hline & No. & $\%$ & No. & $\%$ & No. & $\%$ & No & $\%$ & & \\
\hline & $(n=2$ & & $(n=9$ & & $(\mathbf{n}=9$ & & $(n=$ & & & \\
\hline Depression & 0 & 0.0 & 4 & 44.4 & 7 & 77.8 & 19 & 67.9 & 5.195 & 0.123 \\
\hline Non depression & 2 & 100.0 & 5 & 55.6 & 2 & 22.2 & 9 & 32.1 & & \\
\hline
\end{tabular}

X2: Chi square test

MC: Monte Carlo

Arabic version of GDS scale was used to assess the risk of depression among participants, and it was found that most of participants (30 participants $=62.5 \%$ ) were

depressed, and only 18 participants $(37.5 \%)$ were nondepressed.

When correlating GDS (as a depression screening tool) and spirometric classification (as a marker for COPD severity), it was found that there is no statistically significant relationship between depression and severity of COPD

\section{Discussion}

In this study, data was obtained from 48 Egyptian elderly COPD patients aged 60 years and more to detect if there is correlation between depression and COPD severity in elderly COPD patient.

By using GDS scale to assess the risk of depression among COPD participants in this study, it was found that most of participants (30 participants $=62.5 \%$ ) were depressed. Like other chronic diseases, patients with COPD have a higher prevalence of depression than the general population does [10]. Many previous studies noted that depression is very common to occur in COPD patients, with prevalence of depression in COPD ranges from $10-42 \%$, which is much higher than in the general population [7] [8]. Another systematic review included eight controlled studies also showed that prevalence of depression was $27.1 \%$ [25.9-28.3] in COPD subjects which is much more than in the control group which was $10.0 \%$ [9.2-10.8] [16].

This study revealed that there is no statistically significant relationship between depression and COPD severity. While another recent study detected that the GOLD groups were related to PHQ-9 items in a parallel manner, also psychological function was found to be related to the progress of COPD severity [14]. These different results between both studies may be because both studies used different depression assessment tools (GDS in the present study and PHQ-9 in von Siemens study), and also may be due to the small sample size of this study. Another author also highlighted that the relative risk of developing depression was highest in patients with severe COPD [10].

There were some limitations to consider in this study. First, since the majority of the participants were male patients, we cannot apply the results to the female patients. Although the prevalence of COPD is increasing in females, in Egypt, it is still much more prevalent in males. Therefore, we could not recruit more female patients with COPD. Another limitation of the study was the relatively small sample size, so further studies involving larger sample size are needed.

\section{Conclusion:}

We concluded that depression is highly prevalent among Egyptian elderly COPD patients. However, there is no statistically significant relationship between depression and COPD severity.

Funding

This research received no specific grant from any funding agency in the public, commercial or not-forprofit sectors.

Conflict of interest

The authors report no conflicts of interest in this work. Conclusion:

\section{References}

[1] DIVO, M., COTE, C., DE TORRES, J. P., CASANOVA, C., MARIN, J. M., PINTO-PLATA, V., ZULUETA, J., CABRERA, C., ZAGACETA, J., HUNNINGHAKE, G. \& CELLI, B. 2012. Comorbidities and risk of mortality in patients with chronic obstructive pulmonary disease. Am J Respir Crit Care Med, 186, 155-61.

[2] BARNES, P. J. \& CELLI, B. R. 2009. Systemic manifestations and comorbidities of COPD. Eur Respir J, 33, 1165-85.

[3] MIKKELSEN, R. L., MIDDELbOE, T., PISINGER, C. \& STAGE, K. B. 2004. Anxiety and depression in patients with chronic obstructive pulmonary disease (COPD). A review. Nord J Psychiatry, 58, 65-70.

[4] MONTSERRAT-CAPDEVILA, J., GODOY, P., MARSAL, J. R., BARBE, F., PIFARRE, J., ALSEDA, M. \& ORTEGA, M. 2017. Overview of the Impact of Depression and Anxiety in Chronic Obstructive Pulmonary Disease. Lung, 195, 77-85

[5] ORVOEN-FRIJA, E., BENOIT, M., CATTO, M., CHAMBOULEYRON, M., DUGUET, A., EMERIAU, J. P., FERRY, M., HAYOT, M., JEANDEL, C., MORIZE, V., NASSIH, K., OUKSEL, H., PIETTE, F., PREFAUT, C., ROCHE, N., DE WAZIERES, B. \& ZUREIK, M. 2010. [Chronic obstructive pulmonary disease (COPD) in the elderly]. Rev Mal Respir, 27, 855-73.

[6] PASCAL, O. I., TROFOR, A. C., LOTREAN, L. M., FILIPEANU, D. \& TROFOR, L. 2017. Depression, anxiety and panic disorders in chronic obstructive pulmonary disease patients: correlations with tobacco use, disease severity and quality of life. Tob Induc Dis, 15, 23.

[7] DOWSON, C., LAING, R., BARRACLOUGH, R., TOWN, I., MULDER, R., NORRIS, K. \& DRENNAN, C. 2001. The use of the Hospital Anxiety and Depression Scale (HADS) in patients with chronic obstructive pulmonary disease: a pilot study. N Z Med J, 114, 447-9. 
[8] KUNIK, M. E., ROUNDY, K., VEAZEY, C., SOUCHEK, J., RICHARDSON, P., WRAY, N. P. \& STANLEY, M. A. 2005. Surprisingly high prevalence of anxiety and depression in chronic breathing disorders. Chest, 127, 1205-11.

[9] MAURER, J., REBBAPRAGADA, V., BORSON, S., GOLDSTEIN, R., KUNIK, M. E., YOHANNES, A. M. \& HANANIA, N. A. 2008. Anxiety and depression in COPD: current understanding, unanswered questions, and research needs. Chest, 134, 43s-56s.

[10] LEE, J. H., PARK, M. A., PARK, M. J. \& JO, Y. S. 2018. Clinical characteristics and related risk factors of depression in patients with early COPD. Int J Chron Obstruct Pulmon Dis, 13, 1583-1590.

[11] QUINT, J. K., BAGHAI-RAVARY, R., DONALDSON, G. C. \& WEDZICHA, J. A. 2008. Relationship between depression and exacerbations in COPD. Eur Respir J, 32, 53-60.

[12] HILL, K., GEIST, R., GOLDSTEIN, R. S. \& LACASSE, Y. 2008. Anxiety and depression in end-stage COPD. Eur Respir J, 31, 667-77.

[13] XU, W., COLLET, J. P., SHAPIRO, S., LIN, Y., YANG, T., PLATT, R. W., WANG, C. \& BOURBEAU, J. 2008. Independent effect of depression and anxiety on chronic obstructive pulmonary disease exacerbations and hospitalizations. Am J Respir Crit Care Med, 178, 913-20.

[14] VON SIEMENS, S. M., JORRES, R. A., BEHR, J., ALTER, P., LUTTER, J., LUCKE, T., SOHLER, S., WELTE, T., WATZ, H., VOGELMEIER, C. F., TRUDZINSKI, F., RIEF, W., HERBIG, B. \& KAHNERT, K. 2019. Effect of COPD severity and comorbidities on the result of the PHQ-9 tool for the diagnosis of depression: results from the COSYCONET cohort study. Respir Res, 20, 30 .

[15] VOGELMEIER, C. F., CRINER, G. J., MARTINEZ, F. J., ANZUETO, A., BARNES, P. J., BOURBEAU, J., CELLI, B. R., CHEN, R., DECRAMER, M., FABBRI, L. M., FRITH, P., HALPIN, D. M. G., VARELA, M. V. L., NISHIMURA, M., ROCHE, N., RODRIGUEZ-ROISIN, R., SIN, D. D., SINGH, D., STOCKLEY, R., VESTBO, J., WEDZICHA, J. A. \& AGUSTI, A. 2017. Erratum to "Global Strategy for the Diagnosis, Management, and Prevention of Chronic Obstructive Lung Disease 2017 Report: GOLD Executive Summary" [Arch Bronconeumol. 2017;53:128-49]. Arch Bronconeumol, 53, 411-412.

[16] MATTE, D. L., PIZZICHINI, M. M., HOEPERS, A. T., DIAZ, A. P., KARLOH, M., DIAS, M. \& PIZZICHINI, E. 2016. Prevalence of depression in COPD: A systematic review and meta-analysis of controlled studies. Respir Med, 117, 154-61. 